\title{
DEVELOPMENT OF TUTORIALS TO PROMOTE SELF-DIRECTED PROGRAMMING LEARNING: APPLICATION TO POSTGRADUATE STUDIES
}

\author{
Theocharis A. Plomaritis ${ }^{1,2}$, Maria Puig ${ }^{2}$, Irene Laiz ${ }^{3}$, Juan José Muñoz-Pérez ${ }^{3}$ \\ ${ }^{1}$ Centre for Marine and Environmental Research (CIMA), University of Algarve (PORTUGAL) \\ ${ }^{2}$ Earth Science Department, Faculty of Marine and Environmental Sciences, University of \\ Cadiz (SPAIN) \\ ${ }^{3}$ Department of Applied Physics, Faculty of Marine and Environmental Sciences, University \\ of Cadiz (SPAIN)
}

\begin{abstract}
Most students graduated in Marine Science or other related disciplines (e.g. Geology, Biology, Chemistry) lack the basic background knowledge in scientific programming and modelling (e.g. Matlab, Fortran, Python), necessary in numerical disciplines such as Physical or Coastal Oceanography. Hence, when they enroll for postgraduate studies in Oceanography they are not able to properly follow the lessons related to the above disciplines and generally become discouraged. Trying to meet the needs of those students during the lessons would result in not accomplishing the course's program, given the fact that MSc programs have concentrated material and are extremely demanding for the students. For this reason, a collaborative effort has been made among various lecturers to develop tutorials in order to promote self-directed learning among the MSc students with the aim of alleviating those deficiencies. These tutorials were applied in two different courses and consisted in: i) a quick-start Matlab guide for NetCDF meteorological and oceanographic data handling and plotting, and ii) the use of a front-end platform for visualising, analysing and evaluating results from the state-of-the-art morphodynamic model XBEACH-G. The above methods helped the students to understand the potential of programming and numerical modelling, as well as, the importance of applying such approaches both in consulting and research-based carriers. Overall, this methodology resulted in a higher level of satisfaction among students because it offered an active, flexible and selfreliant learning method that was adapted to each person's learning pace and difficulties. Finally, the tutorials proved to be an inclusive teaching strategy able to address the needs of students with different backgrounds, learning styles, and abilities, hence providing a more efficient learning environment, in which all students could reach their potential at their own pace and feel equally valued at the end of the course.
\end{abstract}

Keywords: Educational innovation, technical education, tutorials, pedagogy, inclusive teaching.

\section{INTRODUCTION}

A large number of students graduated in technical degrees such as Marine Science, Environmental Science, Geology, Biology or Chemistry have acquired an insufficient knowledge in scientific programming and modelling (e.g. Matlab, Fortran, Python) at the time of graduation. Moreover, most of them show a clear lack of interest toward the mathematical and physical aspects of such degrees, even from the first year. In fact, previous authors have pointed out that the bad reputation of Physics as a difficult and non-attractive subject is mostly due to its problem-solving nature [1], together with the fact that many students either lack the necessary mathematical skills or they do not know how to apply them to solve particular problems in physics [2]. Moreover, in today's era of data-intensive systems both research and consulting working environment are in need of technically competent employees that combine both technical skills (programming and modelling) and problem solving abilities.

When students with a poor background in scientific programming and modelling enrol for postgraduate studies in Oceanography they are not able to properly follow the lessons related to numerical disciplines such as Physical or Coastal Oceanography. Furthermore, it is not possible for the lecturers to meet the needs of those students during the lessons because that would result in not accomplishing the course's program. These facts lead to discouraged scholars. These difficulties have also been observed at the BSc level $[3,4,5,6,7]$. For example, it is common that first-year students enrolling different technical BSc degrees are not able to follow the learning pace of the subject of Physics due to either a poor background knowledge in mathematics and physics $[3,4]$ or simply because they have 
the (wrong) impression that the subject is not related with the degree and quickly become disheartened due to the abstract nature of the subject $[5]$. [3, 4] carried out a teaching innovation project aimed at helping students to acquire the mathematical skills necessary to understand the subject of Physics by developing a set of virtual introductory and reinforcement lessons. More specifically, the authors designed and recorded a series of short-duration videos (4-8 minutes) dealing with basic mathematical concepts that could be consulted anytime by the students. Results showed that overall short videotaped tutorials were a useful reinforcement strategy that helped scholars to understand concepts that remained unclear during the class due to their lack of basic knowledge, hence increasing their motivation and ability to learn. Other learning difficulties also arise when the student has a job and cannot attend the lessons on an everyday basis or in the case of foreign students with an insufficient knowledge of the language the lectures are taught in [7]. These authors showed that making medium-duration ( 15 minutes) video recordings of the lessons were a useful tool to help those students. Similar resources have proved useful for increasing the number of students that pass scientific subjects in graduate courses [8].

The practises mentioned above are part of the inclusive teaching strategies, a teaching approach design to address the needs of students with different cultural, racial, gender or knowledge backgrounds, learning styles and abilities, with the ultimate goal of providing an inclusive learning environment in which every scholar feels equally appreciated. When applied to higher education, inclusive learning and teaching allude to the processes by which curricula, pedagogy and assessment are transferred to students in a meaningful, relevant and accessible way [9]. The individual differences are not only welcomed, but also used to enrich the lives and learning of others. On the other hand, they pursue a conceptual change in scholars provoking a cognitive conflict in order to help the assimilation and accommodation of the new information [10].

The objective of this work was to create an inclusive learning environment among students at the University of Cadiz MSc in Oceanography with the aim of alleviating their poor background knowledge in scientific programming and modelling. In addition, the study investigated the alternative conceptions of learners in order to orientate the teaching-learning process and for the student's self-knowledge. This paper is organized as follows: Section 2 describes the methodology used and the experiments conducted; main results are detailed in Section 3; Section 4 presents the conclusions.

\section{METHODOLOGY}

The students enrolled at the University of Cadiz MSc in Oceanography during the academic year 2016-2017 had a broad variety of educational backgrounds, including BSc in Marine Sciences, Biology and Geology. As a result, a large percentage of them admitted not having the basic background knowledge in scientific programming and modelling (e.g. Matlab, Fortran, Python) nor in numerical calculus, necessary in subjects such as Physical Oceanography and Coastal Oceanography. For this reason, a collaborative effort was made among various lecturers to develop tutorials in order to promote self-directed learning among the students with the aim of alleviating the above mentioned deficiencies. More specifically, three lecturers involved in teaching those two subjects, together with a colleague researcher specialized in pedagogy, designed a teaching strategy based on the inclusive teaching approach that took into account the different background knowledge of each student. On one side, students were directly asked about their programming skills (or lack of them) during the first lesson to raise awareness of their own needs among them; on the other side, the lecturers performed an indirect evaluation of each individual's learning styles and needs during the theoretical lessons through observation and evaluation. Once the students' needs we properly identified, the lecturers developed a series of tutorials that were provided to the students in advance with the aim of promoting inclusivity during the practical lessons.

The tutorials consisted in: i) a quick-start Matlab guide for NetCDF meteorological and oceanographic data handling and plotting, and ii) the use of a front-end platform for visualising, analysing and evaluating results from the state-of-the-art morphodynamic model XBEACH-G [11]. The first group of tutorials were provided as part of the Physical Oceanography subject and intended to teach students how to process meteorological and oceanographic data, starting from the most basic programming commands (e.g. Fig. 1) and gradually progressing until all the subject's content was covered (e.g. Fig.2). 


\section{Antes de empezar a programar}

\section{A veces conviene comenzar los programas con los comandos "clear" y/o "clc"}

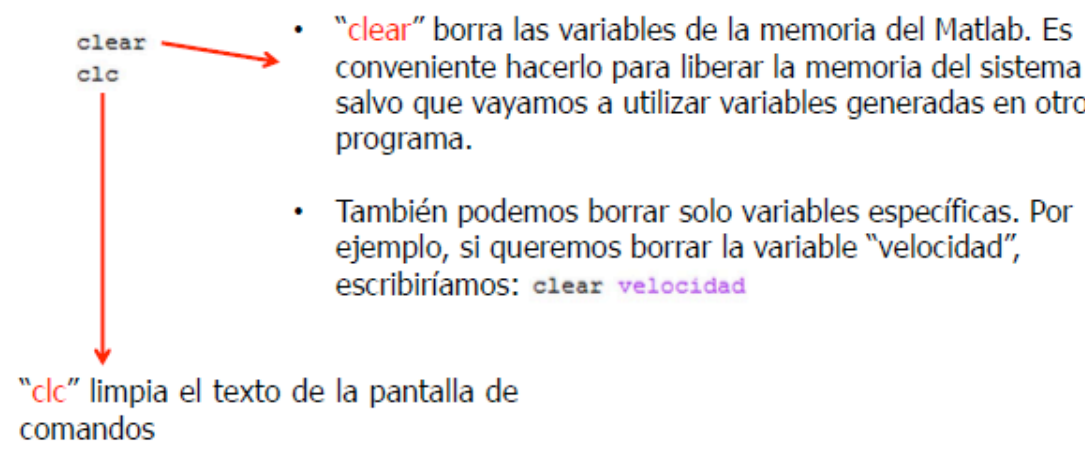

Figure 1. Example of the tutorial showing the meaning and use of two basic programming commands.

\section{Crear una zona geográfica}

Creamos un programa, por ejemplo, "set_region.m", donde extraemos y guardamos los datos de batimetría para la zona de interés:

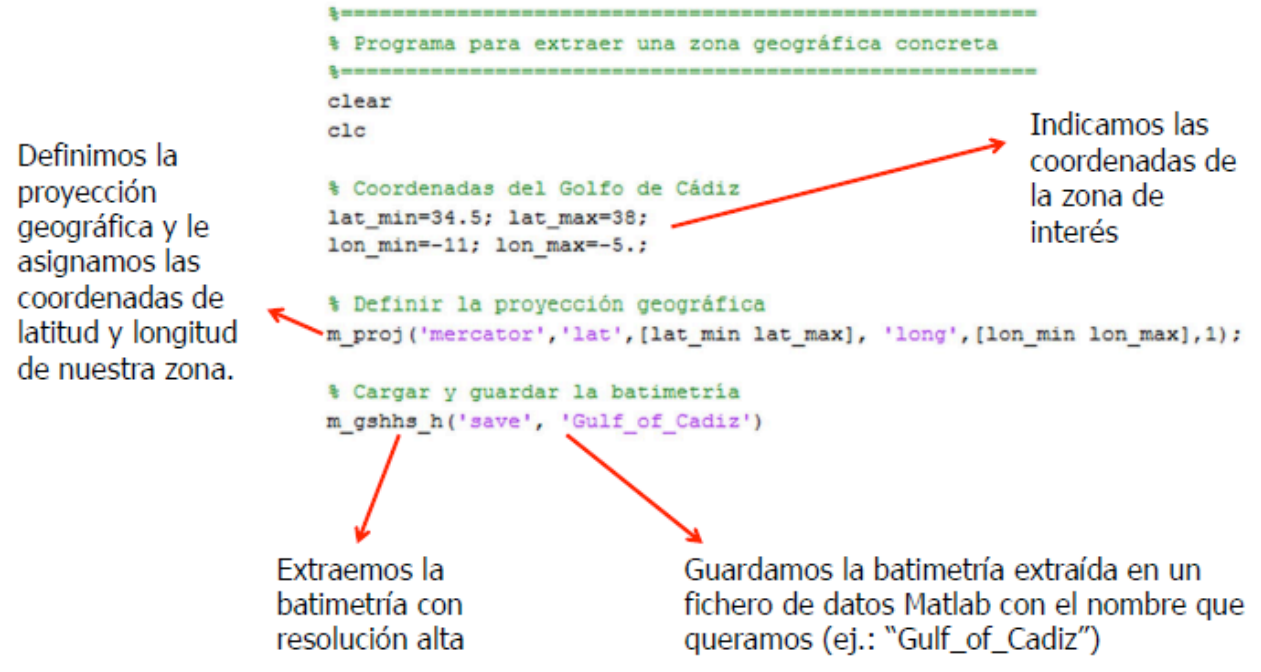

Fig 2. Example of the tutorial showing how to use some advanced data plotting tools

The students were divided into small groups (2-3 students per group) to carry out their assignments; these included analysing and plotting a series of real datasets using most of the techniques explained in the tutorials. It must be pointed out that the tutorials did not directly solved the problems but rather explained how to look for a solution (e.g. Fig.3). In this way, students were encouraged to develop a collaborative learning environment within the group. Finally, the tutorials were general enough to be used in different subjects with different types of datasets. 


\section{Promediar una matriz de 2D}

Si tenemos una matriz, la función "nanmean" calcula el valor medio (ignorando los $\mathrm{NaN}$ ) por columnas.

Ej.: Imaginemos que tenemos una matriz B de 4 filas y 3 columnas que contiene valores NaN. El comando "nanmean(B)" calcula la media por columnas.

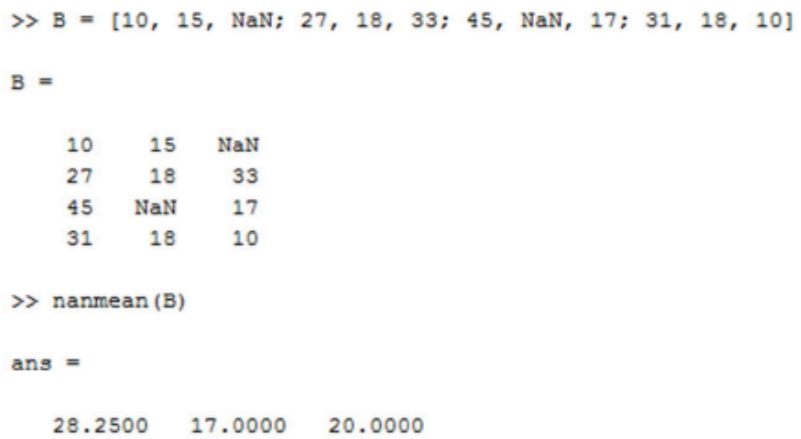

\section{Promediar una matriz de 2D}

Si queremos calcular el valor medio por filas, hay que indicar que queremos hacer el cálculo en la segunda dimensión (las filas).

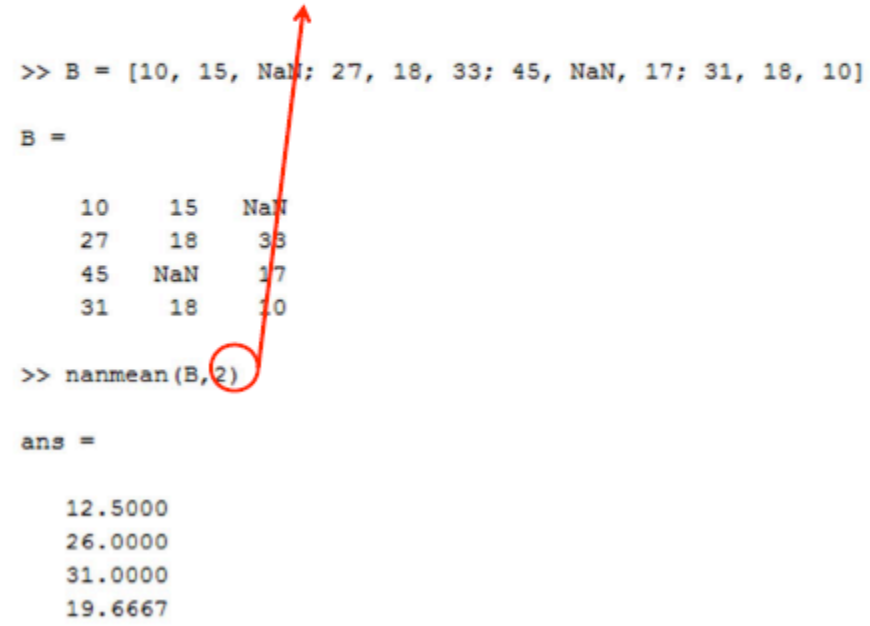

Figure 3. Example of the tutorial showing how to average a $2 D$ array by columns (top panel) and by rows (bottom panel)

The second group of tutorials were specifically designed for the subject of Coastal System Modelling and more specifically in the module of Multiscale Coastal Evolution [12]. When working in a complex and multiscale system, numerical modelling often provides a useful tool in order to separately study processes under idealised conditions. In these tutorials students used the XBeach-G GUI platform to study different coastal morphodynamic processes. As in the previous subject, the students were separated in small groups of 2-3 individuals and, jointly with the lecturer, designed a set of numerical experiments in order to study the above processes. Finally, an assignment was prepared by each group in a form of short scientific paper. For the initialisation in the GUI platform, a tutorial was provided for the scholars to familiarise themselves with the model. 


\section{RESULTS}

\subsection{First group of tutorials}

The Matlab tutorials were used by students in order to solve the tasks assigned. As mentioned before, they did not provide answers to specific questions; rather, they oriented the reader toward the way to find the answer. For example, if they needed to calculate the seasonal mean of a particular meteorological parameter (e.g. wind, atmospheric pressure) distributed on a geographic map, they would have to combine the information given during the theoretical class with the guides shown in the tutorial (Fig. 3) in order to find the explanation of how to average an array along the desired dimension. Since the students were encouraged to visit the lecturer's office whenever they needed help or reassurance, the lecturer used their visits to ask for their personal opinion about the tutorials. Overall, the tutorials become very popular among students. Those scholars with a medium to high numerical and programming background found that the tutorials contained all the information they needed to solve their doubts or to orient them into finding the correct solution. However, those students with a low numerical and programming background said that, although very helpful, the tutorials were not basic enough for them and they needed extra-help from the lecturer or colleague students.

\subsection{Second group of tutorials and GUI platform}

The GUI and tutorial were combined to initialise students with variable levels of programming to scientific modelling. The use of the tutorial allowed the students to work at their preferred pace and at the same time provided them with the freedom to focus their attention to their area of interest. More specifically, after a quick presentation of the interface, the students we able to setup an initial model following the tutorial. The folder structure of the project at the left of the screen (Fig. 4) provides in a glance a total view of the input parameters necessary to execute the model. Students were let to investigate individually and in groups the input parameters before formulating a topic to investigate. It was observed that overall students were primarily driven by their personal scientific interest and tried to see if they were able to introduce them in the model. In more detail, students with a geological background were primarily interested on the effect of the coastal morphology on the waves while those with an oceanography background were more interested in varying the hydrodynamic forcing parameters in the model. As a consequence, the topic selected by each group to investigate and write the report assigned followed the same trend.

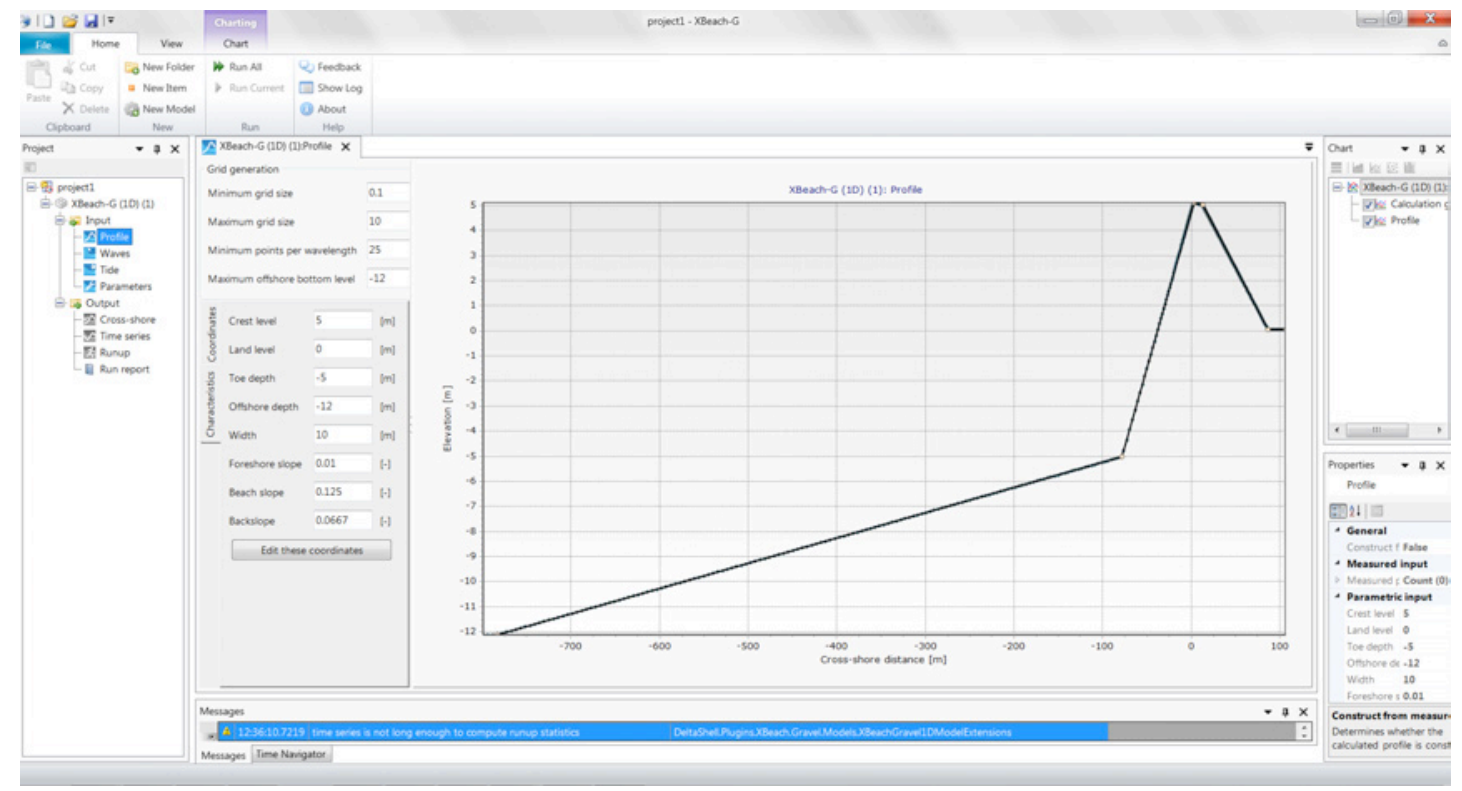

Figure 4. XBeach-G main screen. The input and output folder structure can be observed at the left and the panel to input bathymetry parameters at the right.

Apart from the input, the output structure also offers important advantages to the students. Output parameters can be selected from the Chart panels (Fig. 5) and are automatically displayed in the 
central panel. The student can select to view the results in a cross-section or at specific points; besides, they can choose whether to visualize a particular time stamp or continuous video of the simulation. Finally, some basic statistical parameters are calculated by the GUI. This fast and comprehensive visualization of the results is very important because the student can immediately see the potentials of numerical modelling, both as a research and as a teaching tool. It is known that numerical modelling has a steep learning curve and many times the difficulties in even visualization of the results (due to lack of technical skills) are a major drawback for the students. The present GUI and teaching method provides a solution for scholars to initialize their studies in this area.

Furthermore, XBeach-G is much more than a simple GUI. It is a state of the art model in coastal morphodynamics that is actively been used to simulate numerous coastal processes. The model is open source and, apart of the GUI environment, the full input, output and executable files and parameters are being generated and provided. The output data are stored in a netCDF format; hence, the students are encouraged to use the tutorials and knowledge acquired during the meteorological and oceanographic data handling and plotting module presented in the previous subsection in order to further investigate the XBeach-G output. Making interconnections between subjects and modules within the syllabus of the Master was positively evaluated by the students.

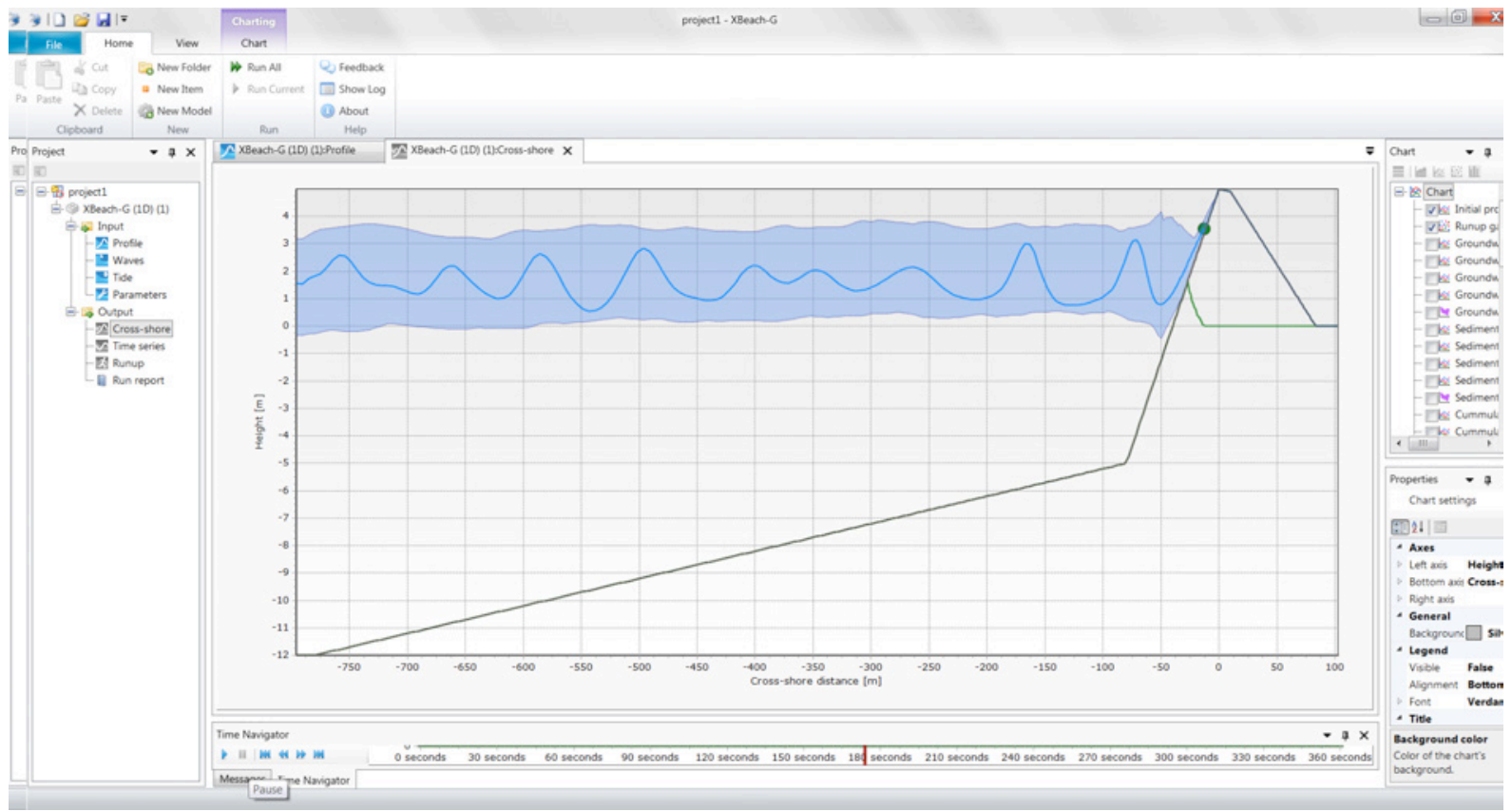

Figure 5. XBeach-G main screen. The input and output folder structure can be observed at the left, the output panel showing the wave characteristics at a certain moment of the simulation (center) and the chart panel (right) that is used to select the different output parameters for viewing.

\section{CONCLUSIONS}

The above methods helped the students to understand the potential of programming and numerical modelling, as well as, the importance of applying such approaches both in consulting and researchbased carriers. Overall, this methodology resulted in a higher level of satisfaction among students because it offered an active, flexible and self-reliant learning method that was adapted to each person's learning pace and difficulties.

The initial conceptual thoughts changed along the process and the methodology accomplished the cooperation between the groups, as the students worked together achieving the common goal of scientific programming and modelling learning. Moreover, it enhanced interpersonal skills and established a comfortable environment where the learners felt free to express their ideas and doubts.

Finally, the tutorials proved to be an inclusive teaching strategy able to address the needs of students with different backgrounds, learning styles, and abilities, hence providing a more efficient learning environment, in which all students could reach their potential at their own pace and feel equally valued at the end of the course. The combination of a GUI and a tutorial was proved an excellent combination to initialise students to numerical modelling and data handling methods. Creating links between 
different courses and modules was positively evaluated by the students because they could make the most of their learning efforts. The knowledge of students' misconceptions led to an adapted teachinglearning process and allowed the design of tutorials, that were adapted to students needs and were successful at overcoming alternative conceptions. In the future, further work on lecturer conceptions should be carried out as they play an important role in the learning process. In addition, an assessment should also be taken into account in order to provide feedback and measure the students' progress.

\section{REFERENCES}

[1] A.O. Ogunleye.Teachers' and students' perceptions of students' problem-solving difficulties in Physics: Implications for remediation. Journal of College Teaching \& Learning 6(7), pp. 85-90, 2009.

[2] J. Tuminaro, E.F. Redish. Understanding students' poor performance on Mathematical problem solving in Physics. AIP Conference Proceedings 720(1), pp. 113-116, 2004.

[3] I. Laiz, F.F. López-Ruiz, A. Aboitiz, A. López-Ruiz. Development of multimedia didactic materials to promote self-directed learning in Physics. Proceedings of ICERI2015 Conference, 16th-18th November 2015, Seville, Spain, pp. 7732-7737, 2015. ISBN: 978-84-608-2657-6.

[4] I. Laiz, F.F. López-Ruiz, A. López-Ruiz. Desarrollo de Material Didáctico Multimedia para el Aprendizaje Personalizado en las Asignaturas de Física. Investigar con y para la Sociedad, Vol. 3, pp. 1897-1901, 2015, ISBN: 978-84-686-6906-9.

[5] I. Laiz, I. Mora-Pérez. On the use of audiovisual resources to motivate first-year students in the subject of physics. Proceedings of the EDULEARN16 Conference, 4th-6th July 2016, Barcelona, Spain, pp. 4720-4724, 2016. ISBN: 978-84-608-8860-4.

[6] J. Guerrero García, P. Arnáiz Sánchez, M.P. García Sanz, L.M. Hernández Abenza. Introducción de las pizarras digitales interactivas en la enseñanza presencial y no presencial, pp. 353-364, 2010. ISBN: 978-84-8371-319-8.

[7] P. López-García, M. Navarro-Pons, J.J. Muñoz-Pérez, G. Anfuso-Melfi. Audiovisual resources as a useful tool to improve the teaching of Coastal Engineering (Marine Science BSc degree). Proceedings of EDULEARN14 Conference, 7th-9th July 2016, Barcelona, Spain, pp. 61176124, 2014. ISBN: 978-84-617-0557-3.

[8] M. Navarro-Pons, J.J. Muñoz-Pérez, G. Anfuso, J. Román-Sierra, L. Moreno. Success on increasing number of students that pass the coastal engineering subject. Proceedings of EDULEARN14 Conference, 7th-9th July 2016, Barcelona, Spain, pp. 4443-4448, 2014. ISBN: 978-84-617-0557-3.

[9] C. Hockings. Inclusive learning and teaching in higher education: a synthesis of research, 2010. Retrieved from https://www.heacademy.ac.uk/

[10] G.J. Posner, K.A. Strike, P.W. Hewson, W.A. Gertzog. Accomodation of a Scientific Conception: Toward a Theory of Conceptual Change. Science Education 66(2), 211-227, 1982.

[11] McCall, R.T., G. Masselink, T.G. Poate, J.A. Roelvink, L.P. Almeida, M. Davidson, and P.E. Russell, Modelling storm hydrodynamics on gravel beaches with XBeach-G. Coastal Engineering, 2014. 91(0): p. 231-250.

[12] Roelvink, D. and A.J.H.M. Reniers, A guide to modeling coastal morphology. Advances in Coastal and Ocean Engineering. Vol. 12. 2011: World Scientific. 